\title{
Önden yüklemeli bir çamaşır makinesinin sonlu elemanlar yöntemiyle dinamik olarak modellenmesi
}

\author{
Mehmet Özer ${ }^{1}$, Atakan Altınkaynak $^{1 *}$, Vedat Temiz ${ }^{1}$, Turhan Mutlu ${ }^{2}$ Tuğba Dışpınar², A. Kadir Özgen², Murat Yücel ${ }^{2}$ \\ ${ }^{1}$ İstanbul Teknik Üniversitesi, Makina Fakültesi, Makina Mühendisliği Bölümü, 34437, Beyoğlu, İstanbul, Türkiye \\ ${ }^{2}$ BSH Ev Aletleri San. ve Tic. A.Ş., 59501, Çerkezköy, Tekirdağ, Türkiye
}

\section{Ö N E Ç I K A N L A R}

- $\quad$ Bir çamaşır makinesi için sıkma aşamasının sayısal olarak modellenmesi

- Dinamik analizde rulmanların modellemesi

- $\quad$ Sayısal modelin doğrulanması

Makale Bilgileri

Geliş: 07.07.2015

Kabul: 05.10.2015

DOI:

$10.17341 /$ gummfd.78923

Anahtar Kelimeler:

Çamaşır makinesi

rulman analizi,

sonlu elemanlar yöntemi,

dinamik analiz

\section{ÖZET}

$\mathrm{Bu}$ çalışmada, önden yüklemeli bir çamaşır makinesinin sıkma aşaması sonlu elemanlar metodu ile modellenerek çamaşır makinesindeki parçaların yer değiştirmeleri ve parçalar üzerindeki gerilmeler öngörülmeye çalışılmıştır. Yapılan sayısal modellemede, dengesiz kütlenin etkisiyle oluşan merkezkaç kuvvet, tambur yüzeyine dinamik olarak etkitilmiştir. Bu etki, tambur hareket ettirilmeden dengesiz kütle hareket ettirilerek sağlanmıştır. Ayrıca çalışma kapsamında basitleştirilmiş rulman modellenmesi de gerçekleştirilmiştir. Çalışma sonucunda belirli bölgelerden ölçümler yapılarak mevcut olan deneysel verilerle karşılaştırma yapılmış ve sonuçların uyumlu olduğu görülmüştür. Bu çalışmada elde edilen sonuçların, çamaşır makinesinin farklı bölgeleri için tasarım değişiklikleri ve iyileştirmeler için yol gösterici olması amaçlanmıştır.

\section{Dynamic analysis of front-loading washing machine using finite element method}

\author{
H I G H L I G H T S
}

- Numerical modelling and analysis of the spinning phase of a washing machine

- Bearing modelling in a dynamic analysis

- Validation of the numerical model

Article Info

Received: 07.07.2015

Accepted: 05.10.2015

DOI

$10.17341 /$ gummfd.78923

Keywords:

Washing machine

bearing analysis,

finite element method,

dynamic analysis

\section{GIRISŞ (INTRODUCTION)}

Son yillarda malzeme teknolojileri ve imalat yöntemlerindeki gelişmeler birçok makinede tasarım ve malzeme değişikliklerine olanak sağlamıştır. Özellikle beyaz eşya sanayi gibi rekabetin yoğun olduğu alanlarda firmalar yenilikçi tasarım ve imalat maliyetinin azaltılması alanlarında birbirleriyle yarışmaktadırlar. Her ne kadar yenilikçi tasarım geliştirmek firmalar için önemli olsa da asıl amaç genel olarak imalat maliyetinin düşürülmesidir. Fakat imalat maliyetleri düşürülürken belirli standartların da yerine getirilmesi gerekmektedir. Ayrıca ürünün pazara

\footnotetext{
*Sorumlu Yazar/Corresponding author: altinkayna@itu.edu.tr / 02122931300 / 2448
} 
çıkış süresinin rekabet dolayısıyla kısalmasıyla oluşan baskılar, tasarımda hata yapma ihtimalini arttırarak, firmalar için zarar etme riski doğurmaktadır. Bunun önüne geçilebilmesi için yapılacak çalışmanın metodolojik bir şekilde planlanması ve çeşitli yazılım programlarının kullanımı gerekmektedir. Genel olarak, çamaşır makinesi ve diğer ticari ürünler için yapılan çalışmalar sonucu elde edilen bilgilerin büyük bir kısmı üretici firmalar tarafindan koruma altına alındığından bu konularda yapılmış çalışmalara erişim kısıtlı olmaktadır. Erişilebilir çalışmalardan birinde, çamaşır makinasının dinamik davranışının deneysel ve teorik olarak incelenmesi Bayraktar [2] tarafından yapılmıştır. Bu çalışmada, "Sonlu Elemanlar Yöntemi”, "Deneysel Modal Analiz Yöntemi” ve "Bileşen Mod Sentezi Yöntemi" kullanılmıştır. Oluşturulan çamaşır makinası modeli $0-400 \mathrm{~Hz}$ için sınanmıştır. Öncelikle çamaşır makinesini oluşturan parçaların elastiklik modülü ve yoğunluk gibi malzeme özellikleri standart deneyler ile ölçülmüştür. Daha sonrasında sonlu elemanlar modeli oluşturularak yapının ilk titreșim modu hesaplanmıştır. Wagner [3] tarafından yapılan çalışmada çamaşır makinesinin dinamik davranışının mekanik olarak modellenmesi açıklanmıștır. Bu model ile çamaşır makinesi gibi çok bileşenli sistemlerde yapılabilecek sadeleştirmeler ve modelleme hakkında ipuçları verilmiştir. Ayrıca bu çalışma dahilinde sistemin hareketi ayrıntılı olarak incelenmiştir. Benzer bir şekilde çamaşır makinasının çoklu gövde analizi ve deneysel çalışması Agnani ve diğerleri [4] tarafından yapılmıştır. Wagner [3] tarafından yapılan çalışmaya nazaran bu çalışmanın üzerinde durduğu öncelikli konu, gürültünün azaltılması olmuştur. Bu çalıșmada devir sayıs1, motor titreşimleri gibi model giriş verileri deneysel çalışma sonucunda elde edilmiştir. Wagner [3] tarafından yapılan çalışmada olduğu gibi yay ve damperlerin modellenmesi için gerekli bilgiler deneyler sonucunda belirlenmiştir. Ayrıca motor titreşimi de deneyler ile ölçülerek sisteme dişardan giriş olarak verilmiștir. $\mathrm{Bu}$ çalışmada gruplar halinde modelleme yapılmış ve bileşenler rijit olarak modellenmiştir. Diğer bir deyişle, sistem; yay, damper ve kütle bileşenleriyle basitçe modellenmiştir. Böylelikle çoklu gövde analizinin çözümleme süresi kısaltılmıştır. Mitsuishi ve Nagao [5] çamaşır makinelerinde sıkma aşamasını sonlu elemanlar ile modelleyerek sonuçları deneysel veriler ile karşılaştırmışlardır. Çamaşır makinesi modellemesini iki kısımda incelemişler ve öncelikle hareketsiz parçalar (dönmeyen) için frekans cevabı analizi yapmışlardır. İkinci olarak ise, hareketli parçalar için lineer statik yapısal gerilme analizi uygulamışlardır. Bu aşamada, hareketsiz parçalar ile bu parçaların temasta olduğu yüzeyler için ilk analizlerden elde edilen sonuçlar sınır koşullarını oluşturmuştur. Çamaşırların sıkılması esnasında dengesiz yükün dengeleyicisi rolündeki su için ise hesaplanan kuvvet modele etkitilmiştir. Weili ve diğerleri [6] yaptıkları çalışmada çamaşır makinesinde mil ve tambur destek parçası için gerilme durumunu incelemişlerdir. Sıkma sırasındaki çamaşır ve suyun oluşturduğu dengesizlik etkisini basitleştirerek eksenden kaçık kütle olarak kabul etmişler ve bu doğrultuda hesaplar yaparak merkezkaç kuvvetini tambur destek parçasına etkitmişlerdir. Motor kayışı gibi unsurların etkisi ihmal edilmiş ve mil, iki rulman ile desteklenecek şekilde sınır şartlarını belirlemişlerdir. Çözümlemede statik model kullanıldığından dolayı tambur destek parçasında dönme sırasında farklı açılarda oluşabilecek kuvvetlerin hesaplanması amacıyla analiz, farklı açılarda yükleme koşulları ile tekrarlanmıştır. Çalışma sonucunda, Weili ve diğerleri [6] dinamik olan bir sistemi çeşitli indirgemeler ve kabuller ile modellemişlerdir. Kurvinen ve diğerleri [7] çalışmalarında bilezik ile bilya arasındaki sürtünme kuvveti ve elasto-hidrodinamik etkiyi göz ardı ederek rulman modelleri oluşturmuştur. Modellerde bilyalar üç boyutlu olarak sisteme dahil edilmiş ve bilya bilezik arasında lineer olmayan Hertz teması [8] tanımlanmıştır. Birinci rulman modelinde merkezkaç ve jiroskopik etki ihmal edilirken, ikinci modelde bu etkiler sisteme dahil edilmiştir. Sistemler farklı dönme hızlarında bilya rijitlikleri için test edilmiştir. Elde edilen sonuçlarda $2000 \mathrm{rpm}$ altındaki hızlarda rijitlik değerlerinin iki model için de aynı olduğu görülmüştür. Chunjun [9] yaptığı çalışmada bilyalı rulmanların modellenmesi ve analizi ile ilgili çalıșmıștır. Çalışmanın ilk bölümünde eksenel yüklü bilyalı rulmanın, radyal rijitliğine etki eden faktörleri incelenmiştir. Ayrıca rulmanlarda boyutların tepki kuvvetlerine olan etkisi de bu çalışma kapsamında incelenmiştir. $\mathrm{Bu}$ aşamada kontrollü deneye başvurulmuş, standart bir rulman seçilerek bilya boyutu, iç ve dış bilezik çapları gibi parametreler değiştirilip bu parametrelerin etkileri gözlemlenmiştir. Chunjun [10] çalışmasının ikinci bölümünde ise bilyalı rulmanların farklı şekillerde modellenmesi üzerinde durmuștur. İlk olarak rulmanı herhangi bir indirgeme veya kabul yapmaksızın bütün olarak modellemiştir. Ardından tek bir bilya üzerine yoğunlaşarak eksenel simetriden yararlanmıştır. Bu aşamada bilya ile bilezik arasındaki temas parametrelerini değiştirerek sistemin durumunu incelemiştir. Bir sonraki adımda ise bilyaları katı olarak modellemek yerine aynı rijitlik değerlerine sahip olan bir dizi çubuk eleman ile modellemiştir. Çubuk eleman sayısını değiştirerek elde edilen sonuçları katı model ile elde edilen sonuçlar ile karşılaştırmış, bunun sonucunda efektif çalışabilen basitleştirilmiş bir rulman modeli elde etmiştir. Yapılan çalışmada, önden yüklemeli çamaşır makineleri için bir sayısal model oluşturulmuş ve bu model dinamik olarak yüklenerek modelin zamana bağlı sayısal analizi gerçekleştirilmiştir. Bu analizlerin gerçekleştirilmesi ile literatüre sağlanan katkılar şu şekilde ifade edilebilir: (1) Sayısal analizlerde kullanılabilecek basitleștirilmiş bir rulman modeli oluşturulmuştur, (2) Oluşturulan rulman modeli kullanılarak çamaşır makinesinde birbirine göre hareketli durumda bulunan başta tambur ve kazan olmak üzere tüm temel parçaların üç boyutlu olarak zamana bağlı yer değiştirmeleri ve parçalar üzerindeki gerilmeler elde edilmiştir. Yapılan literatür araştırmasında, çamaşır makineleri ile ilgili bu kapsam ve büyüklükte bir çalışma bulunamamıştır. Bu çalıșmada oluşturulan modelin, çamaşır makinelerinde gelecekte yapılabilecek tasarım değişiklikleri için yol gösterici olması amaçlanmaktadır. 


\section{DENEYSEL MODEL (EXPERIMENTAL MODEL)}

Yapılan deneylerde çamaşır makinesinin sıkma süresince davranışı modellenmeye çalışılmıştır. Bunun için, öncelikle sıkma sırasında makine içerisindeki çamaşırlardan kaynaklanan dengesizliği hesaba katacak bir çözüm uygulanmaya çalışılmıştır. Bunun için tambur yüzeyine bir levha yerleştirilmiş ve tambur $1100 \mathrm{rpm}$ ile döndürülmüştür. Böylece dönen tamburda yer alan levha, merkezkaç etki ile tambur yüzeyine kuvvet uygulamaktadır. $3130 \mathrm{~N}$ olarak hesaplanan bu kuvvet radyal yönde olup, eksenden kaçık çamaşır kütlesinin tambur yüzeyinde oluşturduğu kuvveti modellemektedir. Deney düzeneğine giriş verileri bu şekilde oluşturulduktan sonra çıkış verilerinin elde edilebilmesi için makine üzerine lazer ile ölçüm yapan bir deplasman sensörü konumlandırılmıştır. Kazan üzerinde konumlandırılan bu sensör ile tamburun kazana göre düşey yöndeki yer değişimi ölçülmüştür. Deney düzeneğindeki dengesiz kütleyi temsilen yerleştirilen ağırlık ve ölçüm için kullanılan sensörün konumları Şekil 1'de verilmiştir.

a)
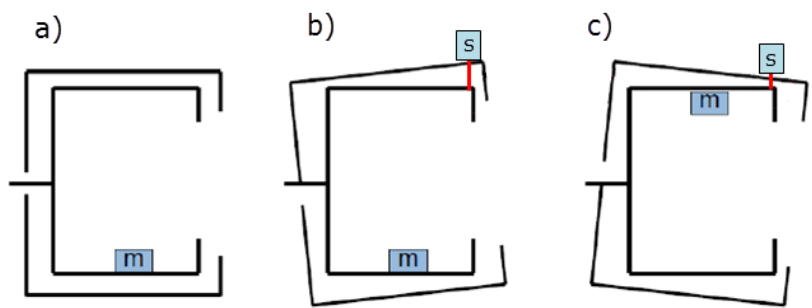

Şekil 1. Deney düzeneğinde dengesiz kütle $(m)$ ve deplasman sensörünün $(s)$ yerleşimi. a) hareketsiz halde b)c) hareketli halde (Location of unbalanced mass (m) and displacement sensor (s) a) at rest b)-c) rotating)

\section{SONLU ELEMANLAR MODELI (FINITE ELEMENT MODEL)}

\subsection{Esas Çevre Büyüklüklerinin Tespiti \\ (System input and output parameters)}

Esas çevre büyüklüklerinin belirlenmesi kısmında sayısal model için elimizde olan bilgiler giriş büyüklüklerini gösterirken, yapılan işler sonucunda elde edilmesi amaçlanan büyüklükler çıkış büyüklüklerini göstermektedir. $\mathrm{Bu}$ çalışma için giriş büyüklükleri; çamaşır makinası geometrisi, dengesiz kütlenin büyüklüğ̈̈, dengesiz kütlenin konumu, tamburun birim zamandaki devir sayısı, motor gücü, yay ve damper özellikleridir. Bu çalışma kapsamında genel ilgi duyulan çıkış büyüklükleri ise; model genelindeki yer değiştirmeler, model genelindeki gerilmeler ve seçilen bölgeler için bağıl yer değiştirmelerdir. Şekil 2' de sisteme giriş ve sistemden çıkış büyüklükleri ayrıntılı olarak verilmiştir. Çamaşır makinesi; rulman bölgesi, tambur, kazan ve kazanın bağlı olduğu yay ve damperler birlikte modellenmiştir. Milin tahrik edildiği motor ise modellenmemiş olup, kayıştan kaynaklanan eğilme ve burulma momentleri mil üstüne etkitilmiştir. Sınır şartları ile ilgili ayrıntılı bilgi "Sınır Şartları" kısmında verilmektedir.

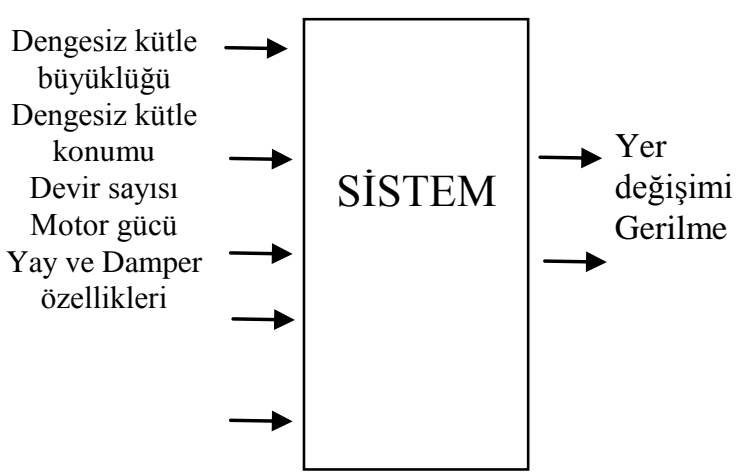

Şekil 2. Giriş ve çıkış parametrelerinin gösterimi (System input and output parameters)

\subsection{Sinır Şartlarl (Boundary Conditions)}

İlk sınır şartı, çamaşır makinesi kazanının gövdeye bağlandığı noktalardadır. İki adet yay ve iki adet damper ile kazan toplam dört noktadan gövdeye sabitlenmiştir. Gövdenin rijit olduğu kabulü yapılarak bu bağlantı noktalarının üç eksen yönünde de yer değiştirmesi kısıtlanmıştır. Ayrıca yay ve damperlerin $y$-ekseni yönünde (Şekil 3) hareket etmediği varsayılmıştır. Böylece kazan için dört noktadan yay ve damperin izin verdiği mertebede yer değiştirmeler gerçekleşmektedir. İkinci sınır şartı, sıkma sırasında dengesiz kütle tarafindan tambura etkiyen kuvvettir. Yapılan deneylerde dengesiz kütlenin $1100 \mathrm{rpm}$ ile dönmesi ile oluşan merkezkaç kuvvet tambura etkimektedir. Oluşturulan sayısal modelde bu kuvvet tambur yüzeyine hareketli şekilde etkitilmiştir. Bunu yapmak için, birbirine ve tambur dönme eksenine dik iki kuvvet sinüs ve kosinüs fonksiyonu ile değişecek biçimde Şekil 3'te gösterildiği gibi tanımlanmıştır.

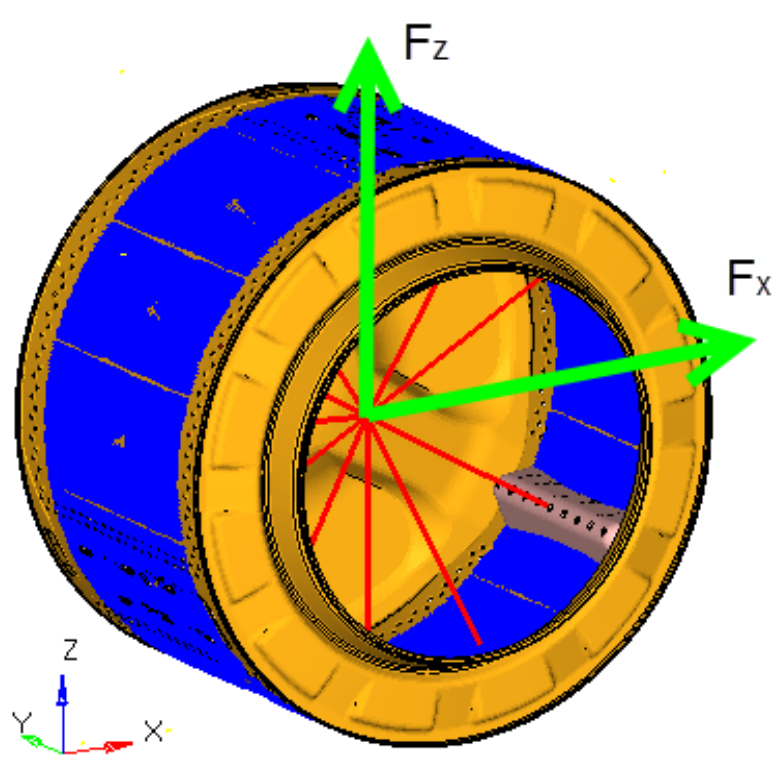

Şekil 3. Dengesiz kütleyi modellemek için kullanılan birbirine dik kuvvet çifti

(Two perpendicular forces which are used to simulate unbalanced force) 
$F_{d}$ dengesiz kütleden kaynaklanan kuvvet $(3130 \mathrm{~N}), \omega$ tamburun açısal hızı, $t$ zaman olmak üzere; birbirine dik iki kuvvetin ilişkisi Eş. 1 ve Eş. 2'de verilmiştir. Tambur merkezinde bu iki kuvvetin bileşkesi olan zamana bağlı döner kuvvet, Şekil 3'te gösterildiği gibi bir boyutlu elemanlar ile tambura etkitilmektedir.

$F_{x}=F_{d} \cdot \sin \left[\omega \cdot \frac{t}{60}\right]$

$F_{z}=F_{d} \cdot \cos \left[\omega \cdot \frac{t}{60}\right]$

Üçüncü sınır şartı, kayış tarafından mile etkiyen kuvvetin modellenmesidir. Kayışın iki ucundaki $F_{k 1}$ ve $F_{k 2}$ kayış çekme kuvvetleri sirasiyla $95 \mathrm{~N}$ ve $30 \mathrm{~N}$ olarak hesaplanmıştır. $\mathrm{Bu}$ kuvvetler dengesiz kütleden dolayı oluşan kuvvetler yanında oldukça düşük kalmaktadır.

\subsection{Sonlu Elemanlar Ă̆ Yapısının Oluşturulması (Creating Geometry and Mesh)}

Ağ örgüsünün oluşturulması sırasında Hypermesh yazılımı kullanılmış ve çamaşır makinesi; mil - rulman, kazan, tambur ve bağlantı bölgeleri olmak üzere 4 ana kısımda incelenmiştir. Tüm parçalar için malzeme özellikleri Tablo 1'de, bağlantı elemanlarının özellikleri ise Tablo 2'de verilmiştir. Modelin oluşturulması sırasında birçok sadeleştirme yapılarak modelin daha kısa sürede sonuçlar vermesi amaçlanmıştır. Çözüm süresinin azaltılması ve yakınsama probleminin aşılması için yapılan en büyük sadeleştirme boyut indirgemesi olmuştur.

Tablo 1. Malzeme özellikleri (Material properties)

\begin{tabular}{llll}
\hline Parça & Malzeme & $\begin{array}{l}\text { Elastiklik } \\
\text { Modülü }[\mathrm{MPa}]\end{array}$ & $\begin{array}{l}\text { Yoğunluk } \\
{\left[\mathrm{kg} / \mathrm{mm}^{3}\right]}\end{array}$ \\
\hline Mil & Çelik & 210.000 & $7,9 \times 10^{-6}$ \\
Rulmanlar & - & 210.000 & $7,9 \times 10^{-6}$ \\
Yıldız destek & Alüminyum & 69.000 & $2,7 \times 10^{-6}$ \\
Tambur & Çelik & 210.000 & $7,9 \times 10^{-6}$ \\
Karıştırıcı & Polipropilen & 2.700 & $1 \times 10^{-6}$ \\
Burç & Dökme demir & 90.000 & $7,9 \times 10^{-6}$ \\
Kazan & Polipropilen & 2.700 & $1 \times 10^{-6}$ \\
(ön ve arka) & & & \\
\hline
\end{tabular}

Tablo 2. Bağlantı elemanları özellikleri (Connector properties)

\begin{tabular}{lll}
\hline Bağlantı elemanı & $\begin{array}{l}\text { Yay katsayısı } \\
{[\mathrm{N} / \mathrm{mm}]}\end{array}$ & $\begin{array}{l}\text { Sönüm katsayısı } \\
{[\mathrm{N} \mathrm{s} / \mathrm{mm}]}\end{array}$ \\
\hline Yay & 5,9 & - \\
Damper & - & $1,6 \times 10^{-4}$ \\
Boşluk eleman & $17.669^{*}$ & - \\
\hline * &
\end{tabular}

*Bir bilya rijitliği Eş. (4) kullanılarak hesaplanmıştır.

Şekil 4'de iki boyuta indirgenen ve üç boyutlu olarak modellenen parçalar gösterilmiştir. Üçüncü boyutu diğer iki boyutuna göre çok daha küçük olan parçalar kabuk olarak modellenmiş ve ağ örgüsü, oluşturulan geometriye uygun olarak tanımlanmıştır. İki boyuta indirgenmiş parçalar; tambur, ön ve arka kazandan oluşmaktadır. Diğer parçalar ise üç boyutlu olarak modellenmiştir. İki boyuta indirgenen parçaların tamamına yakını kabuk olarak modellenirken daha hassas sonuç istenen ve et kalınlığının değiştiği arka kazanın burç ile temasta olduğu bölge üç boyutlu olarak modellenmiştir. Böylece bu kısımda meydana gelen büyük miktardaki gerilme değişimleri hassas olarak öngörülebilmiştir. Diğer bir sadeleştirme, beton blokların ve motorun, taşıyıcı etkisi bulunmadığı için noktasal kütle olarak modellenmesidir. Noktasal kütlelerin konumu seçilirken, indirgenen parçanın geometrik merkezi esas alınmıştır. Oluşturulan kütlenin sisteme entegrasyonu ise, kuvvet ve moment taşıyan 1 boyutlu rijit (rbe2) elemanları ile sağlanmıştır. Oluşturulan noktasal kütlelerin yerleri ve kazana bağlanma noktaları Şekil 5’te verilmiştir.

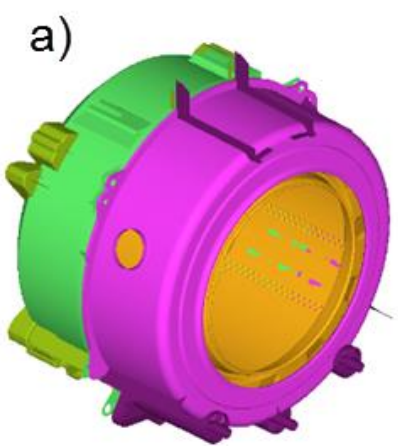

b)

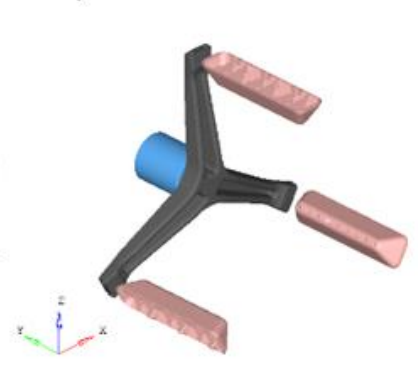

Şekil 4. a) İki boyuta indirgenmiş parçalar, b) üç boyutlu olarak modellenmiş parçalar

( a) Parts modelled in 2D, b) Parts modelled in 3D)

Rulman bölgesinin daha efektif modellenebilmesi için de birkaç değişiklik yapılmıştır. Rulman bilyalarının katı olarak modellenmesi daha çok elemana ve temas yüzeyine ihtiyaç duyacağ için çözüm süresini ve model oluşturma süresini arttırmaktadır. Bunun yerine, bilyaların modellenmesi için bir boyutlu elemanlar kullanılmış ve bu elemanların rijitliği ise Palmgren'in [7] çalışmasına göre belirlenmiştir. $Q$ rulmandaki radyal basma kuvveti, $L$ rulmanda iki bileziğin etkin uzaklığı, $E_{b}$ temastaki çelik için elastiklik modülünü temsil ederken, iki bileziğin bağıl yer değiştirmesi veya bir bilyadaki şekil değiştirme miktarı olan $\delta$, Eş. (3) ile hesaplanabilir. Temasta olan bilya ve bilezik için eşdeğer elastiklik modülü $E_{b}=109.890 \mathrm{MPa}$ olarak belirlenmiştir [7].

$\delta=1,360 \frac{1}{L^{0.8}} \frac{Q^{0.9}}{E_{b}^{0.9}}$

Sistemde kullanılan iki rulmandan daha büyük radyal yüke maruz kalan rulman, tek sira sabit bilyalı rulmandır. $\mathrm{Bu}$ rulman için iki bileziğin etkin uzaklığı olan $L=8,65$ mm'dir. Bilyadaki şekil değişimi Eş. (3) kullanılarak $\delta=$ $9,84 \times 10^{-3} \mathrm{~mm}$ olarak hesaplanmıştır. Eş. (3)'teki ifadenin türevi alınırsa, bir bilya için rijitlik değeri olan $S_{b}$, Eş. (4)'deki gibi ifade edilebilir.

$S_{b}=\frac{\partial \mathrm{Q}}{\partial \delta}=0,817 L^{0.8} E_{b}^{0.9} \delta^{0.1}$ 

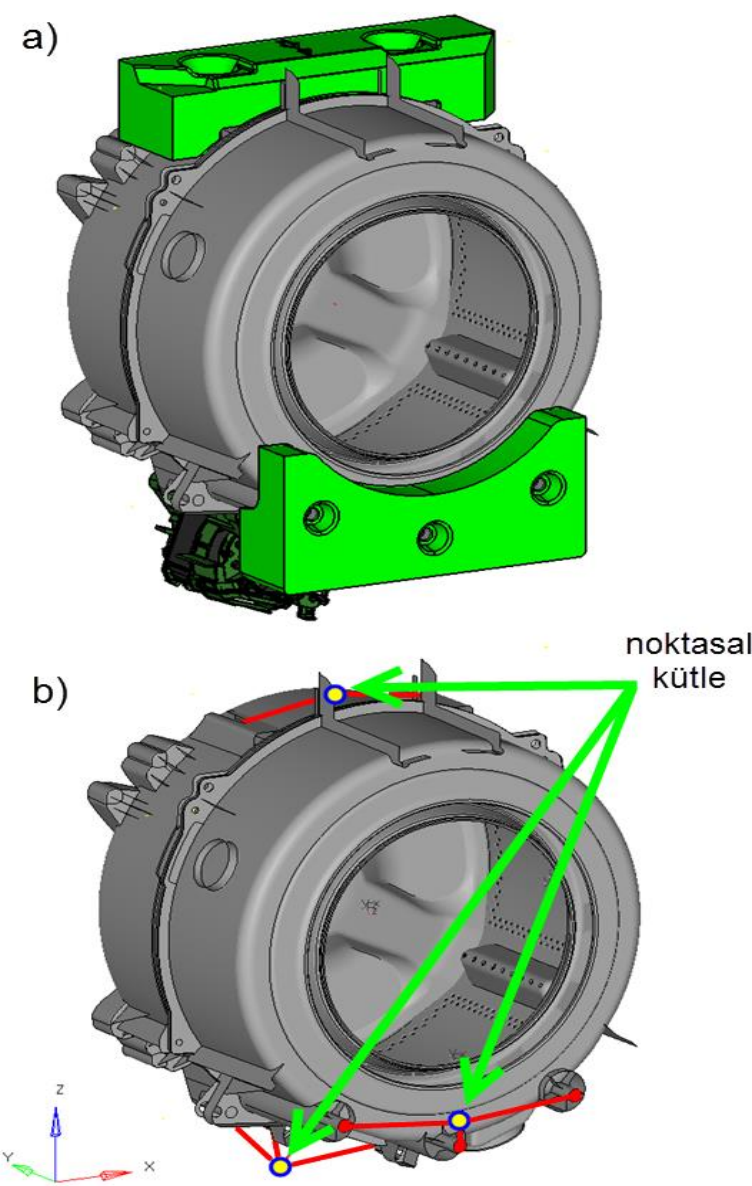

Şekil 5. a) Beton blok ve motor içeren model, b) noktasal kütleler içeren model

(a) Model with mass blocks and motor, b) model with point masses)

Eşitlik sonucunda tek bir bilya için hesaplanan rijitlik değeri $S_{b}=318.046 \mathrm{~N} / \mathrm{mm}$ 'dir. Rulman içindeki bir bilya 18 adet bir boyutlu eleman kullanılarak modellenmiştir. Dolayısıyla, her bir bilyadaki tek bir eleman için rijitlik değeri $S_{e}=$ $17.669 \mathrm{~N} / \mathrm{mm}$ olarak belirlenmiștir. Bilyalarının bir boyutlu elemanlar ile modellenmesi Şekil 6'da gösterilmektedir. Rulman bilyalarının modellenmesi için bir boyutlu boşluk (gap) elemanlar kullanılmıştır. Boşluk elemanlar standart lineer elemanlarda olduğu gibi yay katsayısına sahiptir. Ancak referans değerin altındaki ve üstündeki şekil değiştirme durumları için farklı yay katsayılarına sahip olabilirler [11]. Yapılan çalışmada boşluk eleman yay katsayısı çekme durumu için $0 \mathrm{~N} / \mathrm{mm}$, basma durumu için ise $17.669 \mathrm{~N} / \mathrm{mm}$ olarak ayarlanmıştır. Böylelikle rulmanda radyal kuvvet iletimi sirasinda basma kuvvetine maruz kalan boşluk elemanlar, sahip oldukları rijitlik dolayısıyla kuvvet taşırken; ayrılma eğilimindeki boşluk elemanlar sıfır rijitliğe sahip oldukları için kuvvet taşımayacaktır. Boşluk elemanın kuvvet altında davranışını daha iyi anlatabilmek amacıyla Şekil 7'de bir boşluk elemanın yer değiştirmekuvvet grafiği verilmiştir. Bilyaların tek boyutlu modellenmesi ile model basitleştirilmiş ve çözüm süresi kısaltılmıştır. Tambura yerleştirilen dengesiz yükün 1100 rpm ile tambur yüzeyinde radyal yönde $3130 \mathrm{~N}$ kuvvet oluşturduğundan "Sınır Şartları" bölümünde bahsedilmişti. Bu kuvvetin tek bir noktadan tambur yüzeyine yayılmasında boşluk elemanlar ve bağlandıkları noktaların bağıl yer değiştirmesine izin veren (rbe3) elemanlar kullanılmıştır. Tambur merkezindeki noktadan etkiyen kuvvet, 12 boşluk eleman vasıtasıyla 12 ayrı noktaya dağıtılmıştır. Daha sonra 12 ayrı noktaya dağıtılan kuvvet rbe3 elemanlar kullanılarak tambur yüzeyine dağıtılmaktadır. Kuvvetin dağıtılması için oluşturulan bu yerleşim Şekil 8'de gösterilmiştir. Rbe3 tipi eleman, bağlı oldukları noktaların birbirlerine göre hareketlerini kısıtlamadığı için tambur yüzeyinde ekstra rijitlik oluşmamakta, dolayısıyla dengesiz kütle etkisinde tambur üzerinde meydana genel şekil değişimleri daha rahat gözlenebilmektedir.

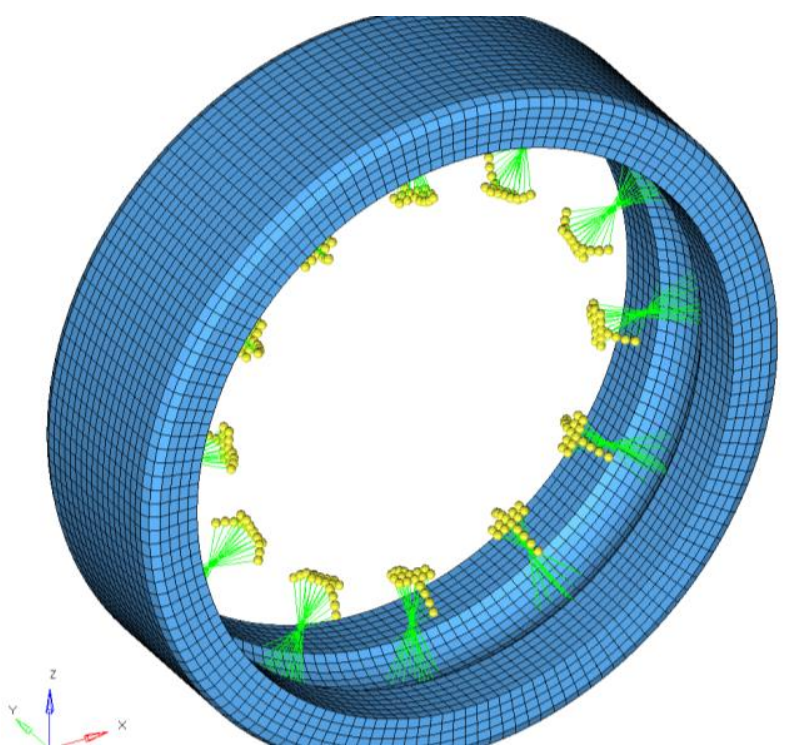

Şekil 6. Bir boyutlu boşluk elemanlar ve dış bilezik modeli (Gap elements in bearing model)

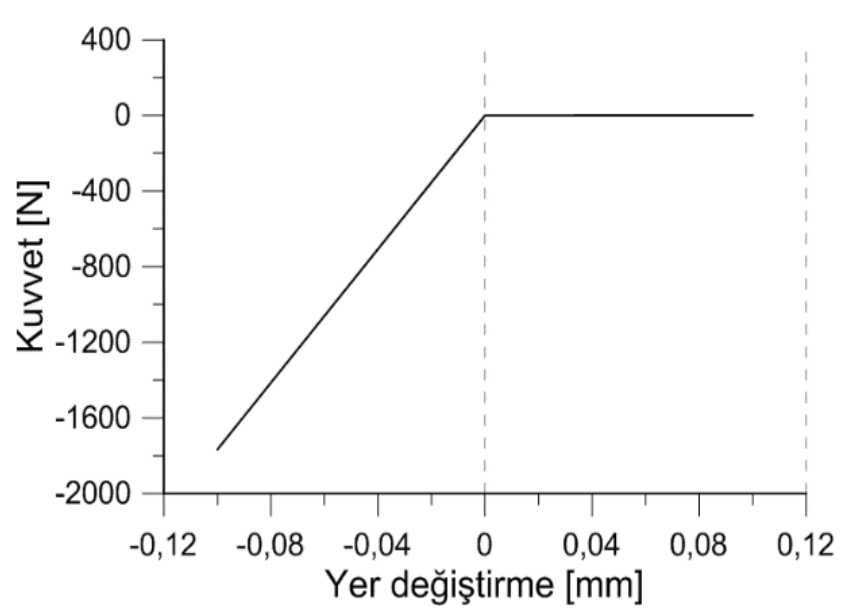

Şekil 7. Boşluk eleman için örnek rijitlik grafiği (Sample stiffness behavior for gap elements)

Modeli oluşturan eleman sayısı ve en büyük eleman boyutları, her bir bölge için ayrı olarak Tablo 3'te verilmiştir. Daha hassas sonuç istenen burç ve rulman gibi bölgelerde kısmen küçük eleman boyutları seçilmiştir. 


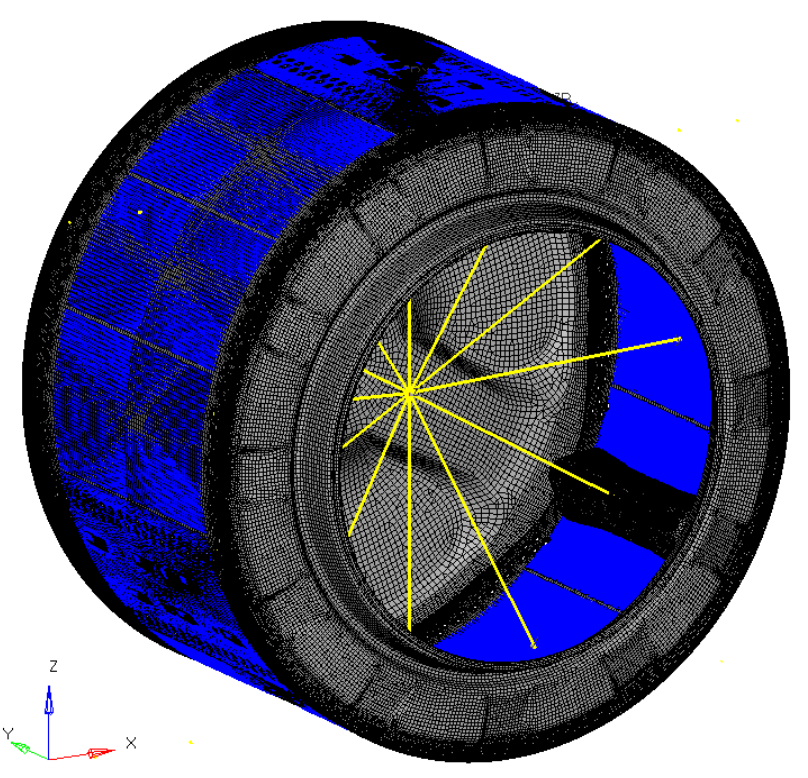

Şekil 8. Boşluk (sarı) ve rbe3 (mavi) elemanlar ile tambur içinde kuvvet dağılımı

(Force distribution through gap (yellow) and rbe3 (blue) elements)

Tablo 3. Parçalara göre eleman sayısı ve maksimum eleman boyutları (Number of elements and element sizes for components)

\begin{tabular}{lcc}
\hline Parça & Eleman Sayısı & $\begin{array}{c}\text { Maksimum Eleman } \\
\text { Boyutu [mm] }\end{array}$ \\
\hline Mil & 182.757 & 7,36 \\
Büyük Rulman & 29.232 & 1,10 \\
Küçük Rulman & 24.642 & 1,10 \\
Yıldız destek & 274.442 & 5,08 \\
Tambur & 240.621 & 7,82 \\
Karıştırıcılar & 281.327 & 5,83 \\
Burç & 534.961 & 3,15 \\
Kazan (arka) & 453.202 & 4,67 \\
Kazan (ön) & 125.514 & 4,97 \\
\hline
\end{tabular}

Dinamik analizde dengesiz yükten ve kayıştan kaynaklanan kuvvetler sıfırdan başlayarak lineer olarak arttırılmıştır. 0,7'nci saniye sonunda dengesiz yükten kaynaklanan kuvvet maksimum değeri olan 3130 N'a, kayıştan kaynaklanan kuvvet ise maksimum değeri olan 120 N'a ulaşmıştır ve bu değerler analizin geri kalan süresi boyunca sabit olarak tutulmuştur. Analizler toplam süre 2 saniye olacak şekilde koşturulmuştur. Sayısal model oluşturulması sırasında tüm parçalar için ağ örgüleri ayrı ayrı oluşturulduğu için montaj edilirlerken parçalar arasında ilişki sağlanması gerekmektedir. Çamaşır makinesi modelinde, parça içinde bağıl hareketli temas içeren tek parça rulmanlardır. Yapılan basitleștirmeler sonucunda rulman bileziklerinin bağıl hareketi de kısıtlanmıştır. Böylece montaj oluşturulduğunda parçaların temas yüzeylerinde izafi hareketlerinin kısıtlanacağı şekilde bağlanması sakınca oluşturmamaktadır. $\mathrm{Bu}$ kabul ile yüzeylerin bağıl serbestlik derecesi azaldığ için modelde küçülme ve çözüm süresinde azalma sağlanabilmiştir. Diğer temas durumları için, parçalar kaynaklı, şekil bağlı veya bütünleşik olarak imal edildiği için bu yüzeylerdeki temas durumu, karşılıklı iki yüzeydeki bağıl hareket sıfır olacak şekilde tanımlanmıştır.

\section{SONUÇLAR VE TARTIŞMA (RESULTS AND DISCUSSION)}

"Sayısal Model" bölümünde bahsedilen model, şartlar ve kabuller kullanılarak deplasman ve gerilme değerleri elde edilmiştir. Fakat elde edilen değerler global eksen takımına göre hesaplanmış sonuçlar olup deneysel sonuçlarla karşılaştırılabilmesi için kazan-tambur bağıl yer değiștirmelerin hesaplanması gerekmektedir. Şekil 9'da, deplasman sensörü bağlanan bölge için global eksende elde edilen tambur (kırmızı renk ile belirtilmişs) ve kazan (siyah renk ile belirtilmiş) deplasman (yer değiştirme) sonuçları verilmektedir. Deneylerde tamburun, ölçüm cihazının bağl1 bulunduğu kazana göre bağıl yer değişimi ölçüldüğünden dolayı sayısal modelde referans koordinat sistemi kazan üzerine yerleştirilerek tamburun bu eksene göre yer değişimi belirlenmiştir. Tamburun kazana göre izafi hareketini zamana bağlı olarak gösteren grafik Şekil 10'da verilmiştir.

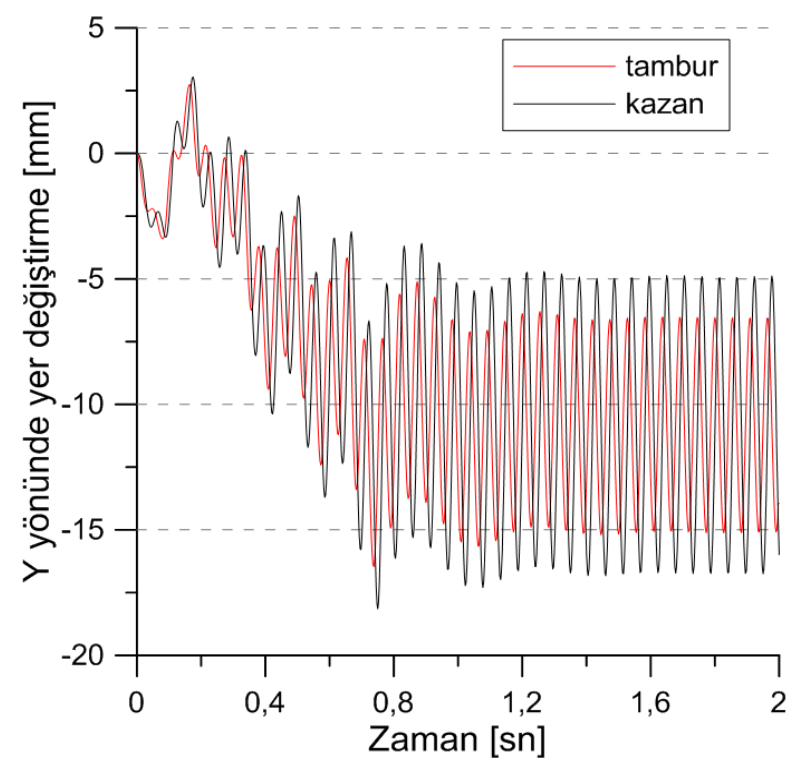

Şekil 9. Kazan ve tambur üzerinde seçilen noktaların zamana göre yer değişimleri

(Tube and drum displacements for selected locations)

Şekil 9 ve Şekil 10 'da görüldüğü üzere sistem toplam 2 saniye için analiz edilmiş ve 1,2 'nci saniyeden sonra dengeye ulaştığı görülmüştür. Yapılan deneylerde, sistemin en yüksek dönme hızı olan 1100 rpm'e çıkması için uygulanan süre analiz süresi için belirlenen 2 saniyeden çok daha fazladır. Zamana bağlı sayısal analizlerde süre ve zaman adımı işlem süresi bakımından çok önemlidir. $\mathrm{Bu}$ bakımdan analizlerde sistemin bir an önce 1100 rpm'e ulaşması sağlanmış ve analizler sistemin kararlı rejime ulaşması durumuna kadar sürdürülmüştür. 
Şekil 11'de sistemin dengeye ulaştıktan sonraki bir an için mil kesitinde oluşan Von Mises gerilme sonuçları verilmektedir. Şekilde verilen sonuçlar, bir tam devir içerisinde en kritik an olarak seçilen 1,465'ncı saniye için elde edilen sonuçlardır. Bu an seçilirken tambur ve kazan üzerinden ölçüm yapılan iki noktanın bağıl yer değiştirmelerinin en büyük olduğu an seçilmiştir. En kritik an her devirde tekrarlanmaktadır. Örneğin 1,465 'nc1 saniyedekine benzer sonuçlar 1,520'nci, 1,575'inci ve 1,630'uncu saniyelerde de elde edilmektedir. Şekil 11'de görülen mil kesitinde gerilme değerleri tarafsız eksenin altı ve üstü için birbirine eşit ve zit yönlüdür. Bu sonuçlar dengesiz yükten dolayı milde oluşması beklenen eğilme gerilmesinden dolayı beklenen sonuçlardır. Milin büyük rulman ile temasta olduğu bölgede gerilmeler, küçük rulman ile temasta olduğu bölgedekine nazaran daha yüksek değerlere sahiptir. Bunun nedeni ise tambur içindeki radyal yöndeki yüklemenin büyük kısmını büyük rulmanın taşıyor olmasıdır.

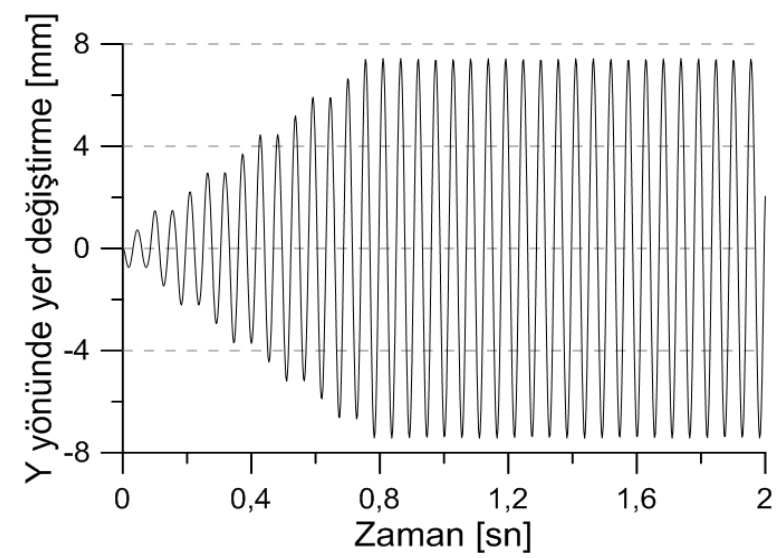

Şekil 10. Tambur üzerinde seçilen noktanın kazan üzerinde seçilen noktaya göre zamana bağlı yer değişimi

(Relative displacement of the drum wrt. the tube)

\section{İşaretli Von Mises gerilmesi [MPa]}

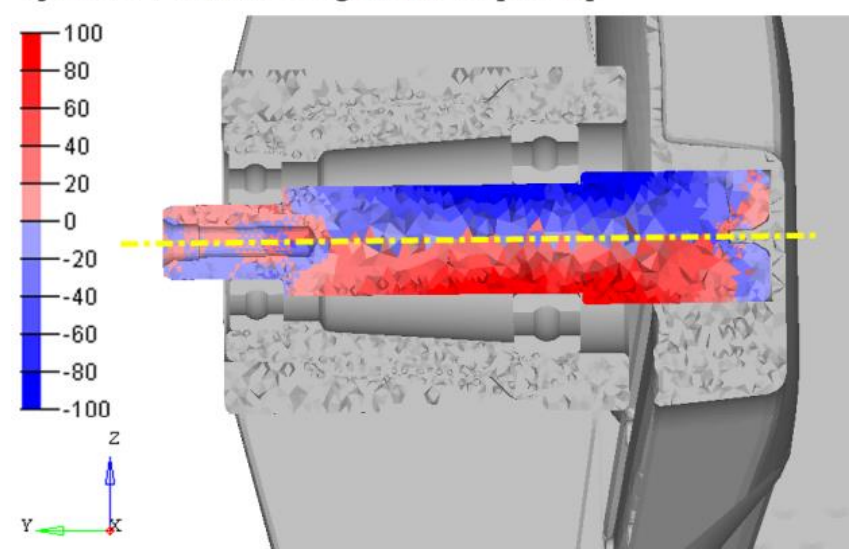

Şekil 11. Mil için Von Mises gerilmesi

(Von Mises Stress results for shaft)

Sayısal analiz sonuçlarının doğruluğunun irdelenmesi için mil üzerinde analitik yöntemlerle basit bir eğilme hesabı yapılmıştır. Oluşturulan modelde mil, rulman ile temasta olduğu bölgelerde radyal yönde hareketi kısttlanacak şekilde mesnetlenmiştir. Dengesiz kütleden ve kaysştan kaynaklanan kuvvetler de mil üzerine uygun şekilde konumlandırılmıştır. $\mathrm{Bu}$ sınır koşulları Şekil 12'de gösterilmiştir. Bir adet kuvvet dengesi ve bir adet moment dengesi eşitliği ile $\mathrm{B}$ ve $\mathrm{C}$ noktalarındaki mesnet tepki kuvvetleri sirasiyla $F_{R I}=-7623 \mathrm{~N}$ ve $F_{R 2}=10633 \mathrm{~N}$ olarak hesaplanmıştır. Buna göre, mil üzerinde oluşan en büyük eğilme momenti $-485.175 \mathrm{Nmm}$ olup milin büyük rulman ile temasta olduğu yerde meydana gelmektedir.

Eğilme momentinden dolayı kesit üzerinde oluşan normal gerilmeleri hesaplamak için Eş. (5) ve Eş. (6) kullanılabilir.

$$
\begin{aligned}
& I_{z z}=\frac{\pi \cdot d^{4}}{64} \\
& \sigma_{\text {maks }}=\frac{M_{\text {maks }}}{I_{z z}} \cdot \frac{d}{2}
\end{aligned}
$$

Eşitliklerde kullanılan; gerilme hesaplanacak kesitteki mil çap1 $\mathrm{d}=25 \mathrm{~mm}$, mil üzerinde oluşan en yüksek eğilme gerilmesi $M_{\text {maks }}=-485.175$ Nmm'dir. $I_{z z}$, Şekil 12'de görülen $z$-ekseni yönündeki atalet momenti, $\sigma_{\text {maks }}$ ise seçilen kesit üzerinde oluşan en büyük gerilme değeridir.
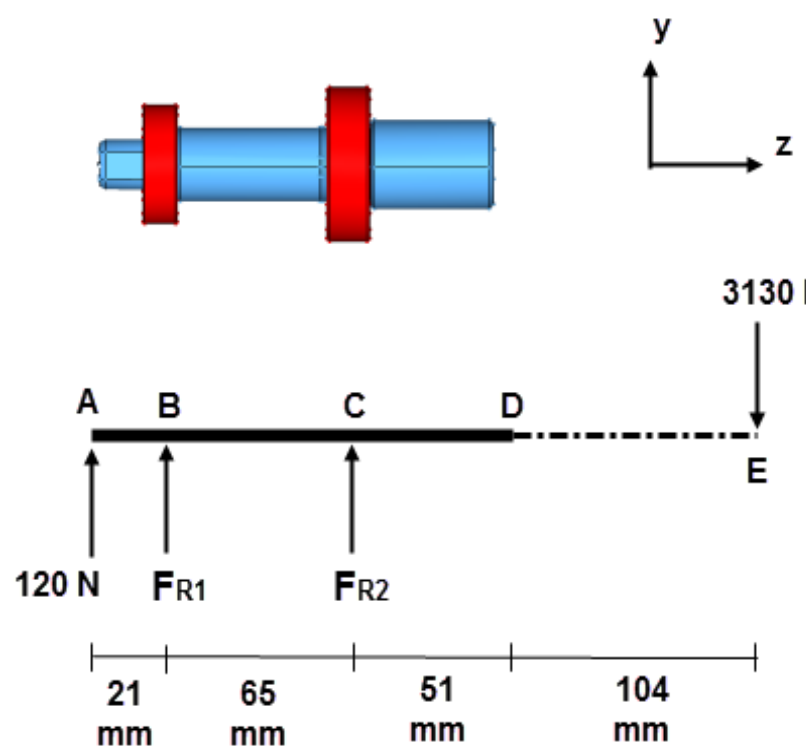

Şekil 12. Mil eğilme hesabında kullanılan sınır şartları (Boundary conditions of shaft deflection problem)

Yapılan hesaplamalar sonucunda mil üzerinde oluşan en büyük gerilme değeri $\sigma_{\text {maks }}=316 \mathrm{MPa}$ olarak bulunmuştur. Sayısal modelde ise mil üzerinde oluşan en büyük Von Mises gerilme değeri $336 \mathrm{MPa}$ 'dır. Bu oluşan farklılık, analitik hesap yapılırken ihmal edilen kayma gerilmeleri ve büyük oranda da çentik etkisinden kaynaklandığı düşünülmektedir. Mil üzerindeki kesit değişimleri, malzemede süreksizlik yaratarak çentik etkisi oluşturmaktadır. 


\section{SONUÇLAR (CONCLUSIONS)}

Yapılan çalışmada önden yüklemeli bir çamaşır makinesi için sıkma aşamasının sayısal olarak modellenmesi amaçlanmıştır. Böylelikle sistem üzerinde tasarım değişikliği öngörülen parçaların sayısal olarak test edilebilmesi sağlanmıştır. $\mathrm{Bu}$ doğrultuda, daha önce yapılmış ilgili çalışmalar incelenerek artı ve eksi yönleri irdelenmiştir. Yapılan çalışmada deneysel olarak oluşturulmuş modelin sayısal modeli oluşturularak çözümlemesi yapılmıştır. Böylelikle hem bilgisayarda kurulan modelin tutarlılığı ölçülmüş hem de yeni oluşturulan modellerde ölçülen değerlerin kıyaslaması yapılabilmiştir. Deneysel ve sayısal olarak elde edilen, kazan ve tamburun birbirine göre maksimum bağ 11 yer değiştirme sonuçları kıyaslandığında sayısal değerler ile deneysel değerler arasında sadece \%2 civarında sapma olduğu görülmüştür. Modellemenin basitleştirilmesi, çözüm süresinin kısaltması için yapılan sadeleştirme ve varsayımlar modelin doğruluğunu olumsuz yönde çok fazla etkilememiş ve nihayetinde deneysel sonuçlarla uyumlu bir sayısal model ortaya çıkmıştır. $\mathrm{Bu}$ durum, çamaşır makinesi parçalarında yapılacak geometrik değişikliklerin, çamaşır makinesinde oluşacak gerilme ve deplasman değerlerini nasıl etkilediğini öngörmede, oluşturulan bu sayısal modelin kullanılabilir olduğunu göstermektedir.

\section{TEŞEKKÜR (ACKNOWLEDGEMENT)}

$\mathrm{Bu}$ makale kapsamında yapılan çalışmalar 5130073 numaralı TÜBITAK projesi kapsamında desteklenmiştir.

\section{KAYNAKLAR (REFERENCES)}

1. Özer, M., Önden Yüklemeli Bir Çamaşır Makinesinin Dinamik Olarak Modellenmesi, Yüksek Lisans Tezi, İstanbul Teknik Üniversitesi, Fen Bilimleri Enstitüsü, 2015.
2. Bayraktar F., Belek H.T., Çamaşır Makinası Dinamik Davranışının Deneysel ve Teorik İncelenmesi, İTÜ Dergisi, 5 (2), 135-144, 2006.

3. Wagner F., Dynamics of Washing Machine, Doktora Tezi, Technische Universität München, 2000.

4. Agnan, A., Cannella F., Martarelli M., Merloni G., Tomasini E.P., Dynamic Characterization of a Washing Machine: Numerical Multi-body Analysis and Experimental Validation, 26th International Modal Analysis Conference, Orlando, USA, 4-7, Şubat 2008.

5. Mitsuishi M., Nagao Y., Washing Machine Dehydration Dynamics Analysis, Nihon Kikai Gakkai Nenji Taikai Koen Ronbunshu, 5, 209-216, 2002.

6. Weili S., Sen Z., Weiwei G., Yuanyuan L., Structure Analysis of Inner Cylinder Components of Drum Washing Machine Based on Ansys/Workbench, Applied Mechanics and Materials, 385-386, 137-140, 2013.

7. Kurvinen E., Sopanen J., Mikkola A., Ball Bearing Model Performance on Various Sized Rotors with and without Centrifugal and Gyroscopic Forces, Mechanism and Machine Theory, 90, 240-260, 2015.

8. Pipaniya S., Lodwal A., Contact Stress Analysis of Deep Groove Ball Bearing 6210 Using Hertzian Contact Theory, International Journal of Innovative Research in Engineering \& Science, 3 (7), 8-16, 2014.

9. Chunjun P., Static Analysis of Rolling Bearings Using Finite Element Method, Yüksek Lisans Tezi, Universität Stuttgart, 2009.

10. Molnar L., Karoly V., Bodai G., Zwierczyk P., Oroszvary L., Simplified Modeling for Needle Roller, Periodica Polytechnica, 54 (1), 27-33, 2010.

11. Landenberger A., El-Zafrany A., Boundary Element Analysis of Elastic Contact Problems Using Gap Elements, Computers \& Structures, 71 (6), 651-661, 1999. 